\title{
Anion-Exchange Study
}

\section{The Indium-Bromide System}

TORKILD ANDERSEN and A. BYE KNUTSEN

Institute of Chemistry and Institute of Physics, University of Aarhus, Aarhus, Denmark

\begin{abstract}
The indium-bromide complex system was investigated using the anion-exchange method given by Marcus and Coryell. The mononuclearity of the complexes was tested and confirmed for the range $3 \times 10^{-5}$ $-3 \times 10^{-4} \mathrm{M}$ indium. The distribution of indium between the resin and the solution was determined in the range $0.1 \mathrm{M}-9.3 \mathrm{M} \mathrm{LiBr}$ by the batch method using the tracer ${ }^{114} \mathrm{In}$. A corrected distribution function was constructed showing the complexes from $\mathrm{InBr}_{2}+$ to $\mathrm{InBr}_{8}{ }^{3-}$, with the successive stepwise formation constants: $\log k_{2}=1.3, \log$ $k_{3}=0.59, \log k_{4}=-0.52, \log k_{5}=-1.6$, and $\log k_{6}=-2.2$. The values of $k_{2}$ and $k_{3}$ agree with published data.
\end{abstract}

$\mathrm{T}$ The application of anion-exchange to quantitative investigations of complex systems, where the ligand is an anion, was introduced by Fronaeus ${ }^{1}$. He showed that plots of the distribution coefficient vs. the ligand concentration gave information about the principal species of complexes in the aqueous phase. Marcus and Coryell ${ }^{2}$ extended the application of the adsorption function to allow the determination of the complex formation constants. Marcus studied the systems $\mathrm{Ag}-\mathrm{Cl}^{3}, \mathrm{Cd}-\mathrm{Cl}{ }^{4}, \mathrm{Fe}(\mathrm{III})-\mathrm{Cl}{ }^{5}, \mathrm{Ag}-\mathrm{S}_{2} \mathrm{O}_{3}{ }^{6}$, and $\mathrm{U}(\mathrm{VI})-\mathrm{PO}_{4}{ }^{7}$ using the anion exchange method ${ }^{2}$. The complex formation constants, obtained by the anion exchange method, were in agreement with data obtained by other physico-chemical methods.

The adsorption of indium into a bromide anion-exchange resin from $\mathrm{HBr}$-solutions is strong $\left(D_{\max }=\sim 4 \times 10^{3}\right)$ in contrast to the adsorption of indium into a chloride anion-exchange resin from $\mathrm{HCl}$-solutions $\left(D_{\max }=\sim 20\right)^{8}$. The system In-Br was investigated more closely using the anion-exchange method. This method should be useful in evaluating the magnitude of the constants for the higher complexes, in particular the constants for $\mathrm{InBr}_{3}$ and $\mathrm{In} \mathrm{Br}_{4}^{-}$, species with zero or unit charge ${ }^{2}$. Table 1 lists the values of the consecutive formation constants of the $\mathrm{In}-\mathrm{Br}$ system obtained by earlier investigations together with the values obtained in this investigation. Spectrophotometry was used as a qualitative check of the interpretation of the ion exchange measurements. 
Table 1.

\begin{tabular}{|c|c|c|c|c|c|c|c|c|}
\hline Investigator & Method & $\begin{array}{l}\text { Ionic } \\
\text { strength }\end{array}$ & $\underset{k_{1}}{\log }$ & $\begin{array}{l}\log \\
k_{2}\end{array}$ & $\begin{array}{l}\log \\
k_{3}\end{array}$ & $\log _{k}$ & $k_{5}^{\log }$ & $\begin{array}{l}\log \\
k_{\mathrm{c}}\end{array}$ \\
\hline Hepler and Hugus ${ }^{\circ}$ & $\mathrm{pH}$ & vary & 2.20 & & & & & \\
\hline Schufle and Eilnad ${ }^{10}$ & Ion-exchange & 1.00 & 1.20 & 0.58 & 0.70 & & & \\
\hline DeSesa 11 & Potentiometric & vary & 3.82 & & & & & \\
\hline Sundén 12 & Potentiometric & 2.00 & 1.98 & 0.58 & & & & \\
\hline Sundén 18 & Extraction & & 1.93 & 0.67 & & & & \\
\hline Cozzi and Vivarelli' & Polarography & 2.00 & 3.80 & 1.00 & & & & \\
\hline $\begin{array}{l}\text { Carleson and } \\
\text { Irving } 15\end{array}$ & Ion-exchange & 0.691 & 2.01 & 1.09 & 0.18 & & & \\
\hline Irving and Rosotti ${ }^{16}$ & Extraction & 1.00 & 2.06 & 1.28 & 0.36 & -0.7 & & \\
\hline $\begin{array}{l}\text { Burns and Hume }{ }^{17} \\
\text { This investigation }\end{array}$ & $\left|\begin{array}{l}\text { Spectrophoto- } \\
\text { metric } \\
\text { Anion-exchange }\end{array}\right|$ & $\begin{array}{l}4.00 \\
\text { vary }\end{array}$ & 2.08 & $\begin{array}{l}1.28 \\
1.3\end{array}$ & $\begin{array}{l}0.60 \\
0.59\end{array}$ & $\begin{array}{r}0.85 \\
-0.52\end{array}$ & -1.6 & -2.2 \\
\hline
\end{tabular}

\section{EXPERIMENTAL}

The distribution coefficients were measured by the equilibration method ${ }^{18}$. The resin used, Dowex $1 \times 10,200-400$ mesh, chloride form, was converted to the bromide form with $\mathrm{HBr}$. The resin was washed with distilled water and dried at $110^{\circ} \mathrm{C}$. The capacity was 3.22 mequiv/g dry resin. The water content was $37.0 \%$.

The indium solutions were prepared from metallic indium, containing ${ }^{14}$ In as a radioactive tracer. The indium concentration was $3 \times 10^{-5}-3 \times 10^{-4} \mathrm{M}$. The lithium bromide was prepared from $\mathrm{Li}_{2} \mathrm{CO}_{3}$ and $\mathrm{HBr}$ and recrystallized twice. Bromide was determined by $\mathrm{AgNO}_{3}$-titration.

The batch samples contained $0.1-0.5 \mathrm{~g}$ resin and $5-10 \mathrm{ml}$ lithium bromide solution. In order to repress hydrolysis, hydrobromic acid was added to the indium and lithium bromide solutions to give a final concentration of around $0.02 \mathrm{M} \mathrm{HBr}$. The resin was shaken with the solution for $48 \mathrm{~h}$ at room temperature. The concentration of indium in the aqueous phase was determined using a well type scintillation counter.

The concentration of $\mathrm{Li}^{+}$and $\mathrm{Br}$ - in the resin phase was determined by a method given by Kraus and Moore ${ }^{19}$.

The spectrophotometric measurements were carried out with recording Cary 14 spectrophotometer using silica cells of 0.100 and $1.000 \mathrm{~cm}$. lengths, wavelength: $200-300 \mathrm{~m} \mu$.

Table 2.

Concentration of ligand $m_{\mathrm{L}, \mathrm{BB}}$ (mole/litre)
Indium-concentration $\times 10^{-4} \mathrm{M}$
Log of indium distribution coefficient $\log D$.

$\begin{array}{lll}0.44 & 0.3 & 1.20 \\ 0.44 & 1.5 & 1.15 \\ 0.44 & 3.0 & 1.20 \\ 1.12 & 0.3 & 1.76 \\ 1.12 & 1.5 & 1.75 \\ 1.12 & 3.0 & 1.78 \\ 4.53 & 0.3 & 3.78 \\ 4.53 & 1.5 & 3.80 \\ 4.53 & 3.0 & 3.74 \\ 5.14 & 0.3 & 3.97 \\ 5.14 & 1.5 & 4.01 \\ 5.14 & 3.0 & 3.98\end{array}$

Acta Chem. Scand. 16 (1962) No. 4 
Table 3. Effects of the variation of the $\mathrm{LiBr}$-concentration.

LiBr-conc. Log of $\mathrm{Br}^{-}$activity Log of In-distribution (moles/litre) function coefficient

$\begin{array}{lrl}0.10 & -1.10 & 0.40 \\ 0.21 & -0.80 & 0.76 \\ 0.31 & -0.63 & 0.98 \\ 0.44 & -0.48 & 1.20 \\ 0.68 & -0.29 & 1.52 \\ 0.87 & -0.17 & 1.60 \\ 0.99 & -0.10 & 1.70 \\ 1.18 & 0.00 & 1.81 \\ 1.38 & 0.09 & 2.00 \\ 1.58 & 0.18 & 2.10 \\ 1.97 & 0.30 & 2.38 \\ 2.46 & 0.46 & 2.50 \\ 2.95 & 0.60 & 3.00 \\ 3.44 & 0.76 & 3.20 \\ 3.80 & 0.86 & 3.45 \\ 4.72 & 1.13 & 3.90 \\ 5.24 & 1.28 & 4.06 \\ 5.66 & 1.40 & 4.20 \\ 6.16 & 1.54 & 4.35 \\ 6.56 & 1.66 & 4.48 \\ 7.08 & 1.81 & 4.75 \\ 7.50 & 1.94 & 4.84 \\ 8.03 & 2.10 & 4.93 \\ 8.44 & 2.22 & 4.97 \\ 8.88 & 2.36 & 4.97\end{array}$

\section{RESULTS}

The effect of variation in the indium concentration is shown in Table 2. The results show that the distribution coefficient is unaffected by changes in the indium concentration, indicating that the complexes are mononuclear in the range $3 \times 10^{-5}-3 \times 10^{-4} \mathrm{M}$ indium. Solvent extraction measurements of Irving and Rosotti ${ }^{16}$ were explained by dimerization of indium in aqueous bromide solutions. Johnson and Kraus ${ }^{20}$, however, demonstrated by molecular weight measurements using an equilibrium ultracentrifuge that indium(III) in $\mathrm{HBr}$ exists only as mononuclear complexes. Table 3 shows the distribution of indium between the resin and the lithium bromide solutions in the range $0.1-9.3 \mathrm{M}$. The values of the activity function for the bromide ligand $a=m_{\mathrm{LiBr}} \gamma_{ \pm(\mathrm{L}, \mathrm{BBr})}$ were obtained from Robinson and Stoke ${ }^{21}$. In Fig. 1 is plotted the logarithms of the distribution coefficient, $D$, vs. the logarithm of the ligand activity.

The spectrophotometric measurements show qualitatively that the complex formation in the system $\mathrm{In}-\mathrm{Br}$ does not stop at a definite complex (e.g. $\mathrm{In} \mathrm{Br}_{3}$ ), but the complex formation is continued for increasing $\mathrm{HBr}$ concentrations. 


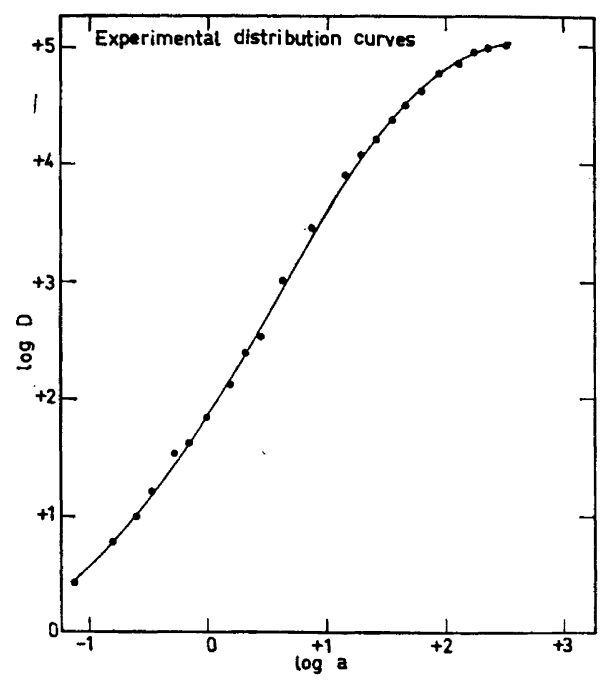

Fig. 1. The anion exchange distribution curve $(\log D)$ plotted vs. the logarithm of the bromide activity function $\left(\log a=\log m_{\mathrm{LiBr}}+\log \gamma_{\mp \mathrm{L}_{\mathrm{iBr}}}\right.$ ) for the absorption of indium from lithium bromide by Dowex 1 bromide-anion exchange resin.

\section{DISCUSSION}

Using the terminology of Marcus and Coryell ${ }^{2}$ the complexed species of indium may be considered to be formed in the reaction:

$$
\mathrm{InBr}_{3} \rightleftharpoons \mathrm{InBr}_{3-i}^{i}+i \mathrm{Br}^{-}
$$

where $i$ is the charge of the complex.

The thermodynamic equilibrium constant for the reaction (1) is:

$$
\beta_{i}=\left(a_{\mathrm{InBr}_{3-i}}\right)\left(a_{\mathrm{Br}}\right)^{i} /\left(a_{\mathrm{InBr}_{2}}\right)=m_{i} \cdot \gamma_{i} \cdot a^{i} \cdot a_{0}-1
$$

where $m_{i}$ is the concentration of the $i$-th complex species, $\gamma_{i}$ the activity coefficient, $a$ is the ligand activity function and $a_{0}$ is the thermodynamic activity of the complex $\operatorname{InBr}_{3}$. The equation

$$
\Sigma m_{i}=a_{0} \Sigma \beta_{i} \gamma_{i}^{-1} a^{-i}
$$

expresses the total concentration of indium in the aqueous phase. An equation analog to (3) expresses the series of complexes, $m$ in the resin phase. If $i=-p$ indicates the charge number of the principal species in the resin, the distribution coefficient $D$ is defined by:

$$
D={ }_{r} m_{-p} / \Sigma m_{i}=\left({ }_{,} \beta_{-p}\right)\left({ }_{r} \gamma_{-p}^{-1}\right)\left({ }_{r} a^{-p}\right) / \Sigma \beta_{i} \cdot \gamma_{i}^{-1} \cdot a^{-i}
$$

as ${ }_{,} a_{0}=a_{0}$ at equilibrium.

Assuming that $\gamma_{i}$ values are essentially independent of $a$, the activity of the ligand concentration, in the successive regions where the corresponding species $\operatorname{InBr}_{3-i}^{i}$ are predominant, and $\gamma_{-p}$ is independent of $a$, the $\log D$ is expressed by 


$$
\log D=\log { }_{r} \beta^{*} \rightarrow p+p \log , a-\log \Sigma \beta^{*}{ }_{i} a^{-i}
$$

when $\beta^{*}{ }_{i}=\beta_{i} \gamma_{i}^{-1}$

As a Donnan equilibrium, $a_{\mathrm{LiBr}}=a_{\mathrm{L}, \mathrm{BBr}}$ is proved to exist, the resin ligand activity function,$a$ can be expressed by the equation:

$$
\log { }_{r} a=\log a+1 / 2\left(\log _{r} m_{\mathrm{Br}}-\log _{r} m_{\mathrm{Li}_{\mathrm{i}}}\right)
$$

If ${ }_{,} a^{0}$ expresses the resin ligand activity function, ${ }_{r} a$ at $a=1$, a correction function, $F_{a}$ is defined as:

$$
{ }_{,} \mathrm{F}_{a}=\log , a-\log , a^{0}
$$

The ideal or corrected distribution coefficient $D^{\circ}$ is defined by:

$$
\log D^{\circ}=\log D-p_{r} F_{a}=\log K_{r}-\log \Sigma \beta^{*} a^{-i}
$$

in which $K_{r}={ }_{r} \beta_{-p}, \gamma_{-p}^{-1},{ }_{r} a^{o}$. According to eqn. (8) the ideal distribution coefficient $D^{\circ}$ should be a function of the complex formation in the aqueous solution only, for a given ion exchange resin.

The maximal co-ordination number of indium is 6 . The ratio between the radius of the indium(III) ion and the radius of the bromide ion shows that the formation of an indium hexabromocomplex is geometrically possible. Woodward and Bill ${ }^{22}$ reported from a study of the Raman spectra of indium salts in the presence of a large excess of bromide, that no tetrahedral $\mathrm{InBr}_{\mathbf{4}}^{-}$ ion is present in the aqueous solution. Burns and Hume ${ }^{17}$ assumed that the indium tetrabromocomplex is $\left[\mathrm{In}\left(\mathrm{H}_{2} \mathrm{O}\right)_{2} \mathrm{Br}_{4}\right]^{-}$with a structure as an octahedron, because indium frequently exhibits hexacoordination. The use of eqn. (8) combined with the assumption of the formation of a hexabromocomplex on the resin as $R_{3} \operatorname{InBr}_{6}$, results in values of the first complex formation constants in the system $\mathrm{In}-\mathrm{Br}$ in agreement with published data obtained by other methods (cation-exchange, extraction and spectrophotometry).

The correction function, $F_{a}$ was calculated by means of the activity values of the bromide ion, the concentration of the lithium ion and the concentration of the bromide ion in the resin phase. The reference point for , $a$, as , $a^{a}$, at $a=1$ is calculated like that,$F_{a}=0$ at this point; ${ }_{a} a^{0}$ was determined to 0.46. It is known ${ }^{19}$ that the resin invasion is small at $\mathrm{a}=1$, but still accessible to reasonably accurate measurements. The values of the correction function ,$F_{a}$ are shown in Fig. 2. The function, ${ }_{f} F_{a}$ for the bromide system is nearly identical with the correction function for the chloride system reported by Marcus ${ }^{2,3}$.

Using the values of,$F_{a}$ in Fig. 2 , a corrected or ideal distribution coefficient $D^{\circ}$ is calculated by eqn. (8).

The average charge number $\bar{i}$ and the average ligand number $\bar{n}$ can be calculated from the slopes of the ideal distribution function:

$$
\frac{\mathrm{d}\left(\log D^{\circ}\right)}{\mathrm{d}(\log a)}=\bar{i}=3-\bar{n}
$$

since the parameters $K$, and $\beta^{*}{ }_{i}$ are taken as constants.

Acta Chem Scand. 16 (1962) No. 4 


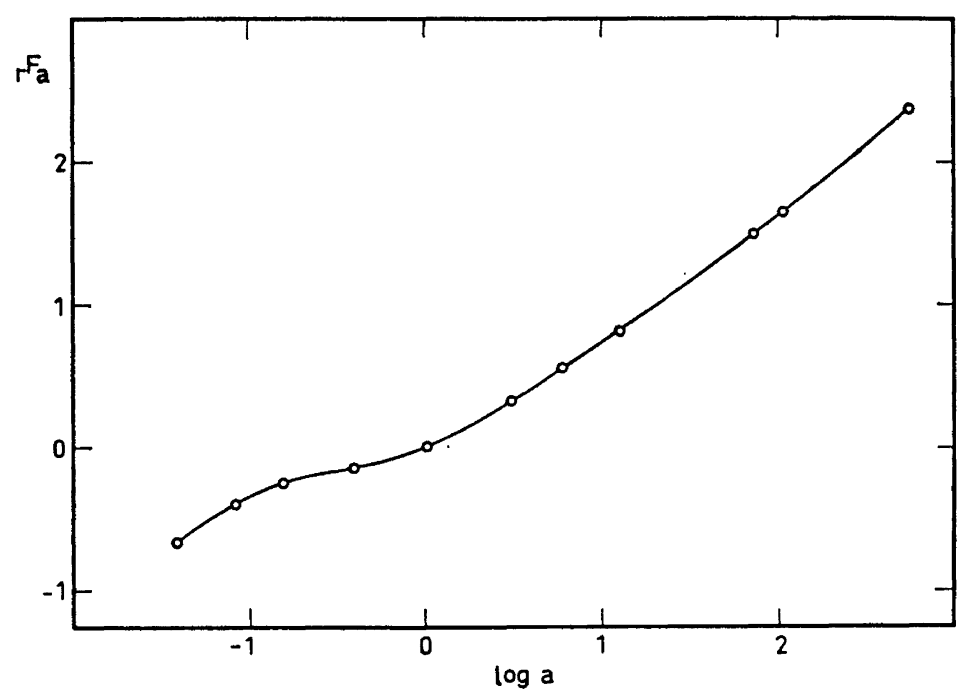

Fig. 2. The activity function, $a$ of bromide in the resin Dowex l-bromide equilibrated with lithium bromide plotted as a function of the bromide activity function $a$ in lithium bromide solutions (logarithmic scale).

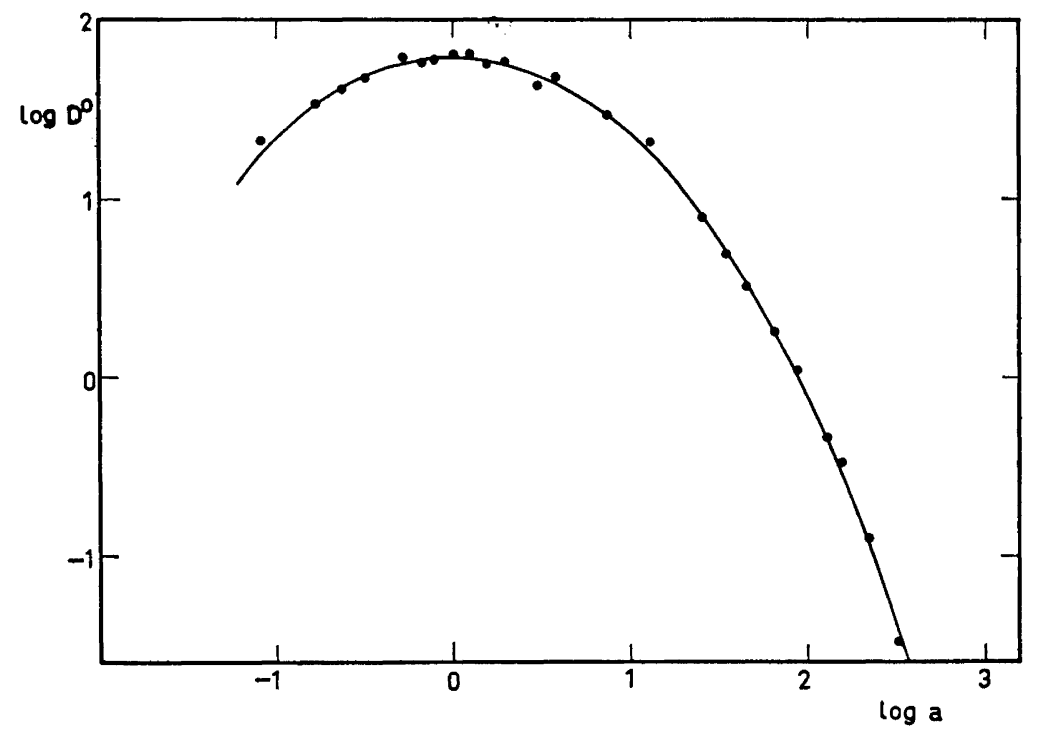

Fig. 3. The corrected distribution curve $\left(\log D^{\circ}\right)$ using the parameter $p=3$ for the predominant resin species $\mathrm{R}_{8} \mathrm{InBr}_{6}$, plotted vs. the bromide activity function (log $a$ ). 
The curve has slopes ranging from approximately +1.6 at the lowest concentration to exactly -3.00 at $9 \mathrm{M} \mathrm{LiBr}$. The value +1.6 refers to $\mathrm{In}_{\mathrm{Br}_{2}^{+}}$ and the value -3.00 to $\operatorname{In~}^{3}{ }_{6}^{3-}$.

The values of the successive formation constants $k^{*}{ }_{i}$ were obtained by the Bjerrum's "half-integral $i$ " method, where, to a first approximation:

$$
\log k^{*}=\log \beta_{i}^{*} / \beta_{i-1}^{*}=-\log a_{(\bar{i}=i-1 / 2)}
$$

The preliminary values, obtained by Bjerrum's method, were applied to calculate the formation constants by Sillen's "curve fitting" method ${ }^{23}$. The values so obtained are: $\beta^{*}{ }_{2}=1.2 \times 10^{-2} ; \beta^{*}{ }_{1}=0.26 ; \beta^{*}{ }_{-1}=0.30$; $\beta^{*}{ }_{-2}=7 \times 10^{-3} ; \beta^{*}-3=5 \times 10^{-5}$. The values of the formation constants

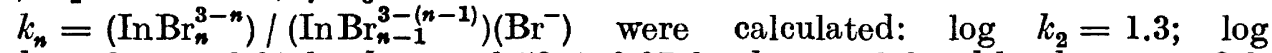
$k_{3}=0.59 \pm 0.08 ; \log k_{4}=-0.52 \pm 0.07 ; \log k_{5}=-1.6$ and $\log k_{6}=\sim-2.2$. It is not possible to determine $k_{1}$ of the experimental results. Log $K_{r}$ is determined as $2.01 \pm 0.04$.

The complex formation constants $k_{2}$ and $k_{3}$ found in the present work are seen to be in reasonable agreement with data obtained by other methods, Table 1. A determination of $k_{1}$ was carried out by spectrophotometric methods similar to that of Burns and Hume ${ }^{17}$. The value so obtained agrees with the value reported by Burns and Hume.

The value of $k_{4}$ agrees with the result of Irving and Rosotti ${ }^{16}$, but deviates from the value reported by Burns and Hume. The spectrophotometric measurements show that the complex formation in the system $\mathrm{In}-\mathrm{Br}$ does not stop at a decided complex, but the complex formation is continued for increasing $\mathrm{HBr}$-concentration. The value $k_{4}$ given by Burns and Hume was determined assuming that the complex In $\mathrm{Br}_{4}^{-}$was the only absorbing species of higher complexes. Making a comparison with the complex formation constants of halogen complexes of the group $\mathrm{Al}, \mathrm{Ga}, \mathrm{In}, \mathrm{Tl}{ }^{24}$ the published data show a marked tendency for the ratio $\log k_{3} / k_{4}>0$, as in the present work.

The parameter $K$, may be used to calculate the equilibrium constant for the reaction

$$
\mathrm{InBr}_{3}(\mathrm{aq})+3 \mathrm{RBr} \rightleftharpoons \mathrm{R}_{3} \mathrm{InBr}_{6}
$$

by dividing $K$, with the $3 \mathrm{rd}$ power of ${ }_{r} a^{02}$. This gives $\log K_{r}-3, a^{0}=2.01$ $-1.38=0.63$ for the logarithm of this constant. A comparison between this value and the value for the corresponding reaction in the solution $\log \beta_{-3}^{*}=$ -4.3 shows that the resin stabilizes the indium hexabromocomplex $10^{5}$-fold.

Acknowledgement. The authors are grateful to professor S. E. Rasmussen for his valuable advice and discussions.

\section{REFERENCES}

1. Fronaeus, S. Svensk Kem. Tidsskr. 65 (1953) 1.

2. Marcus, Y. and Coryell, C. D. Bull. Research Council Israel 8A (1959) 1.

3. Marcus, Y. Ibid. 8A (1959) 17.

4. Marcus, Y. J. Phys. Chem. 63 (1959) 1000.

5. Marcus, Y. J. Inorg. Nuclear Chem. 12 (1960) 287.

6. Marcus, Y. Acta Chem. Scand. 11 (1957) 619.

7. Marcus, Y. Intern. Conf. Peaceful Use Atomic Energy 3 (1958) 465.

Acta Chem Scand. 16 (1962) No. 4 
8. Andersen, T. and Knutsen, A. Bye, Part I. Acta Chem. Scand. 16 (1962) 875.

9. Hepler, L. G. and Hugus, Z. Z. J. Am. Chem. Soc. 74 (1952) 6115.

10. Schufle, J. A. and Eiland, H. M. Ibid. 76 (1954) 960.

11. DeSesa, M. A. Thesis, Mass. Inst. of Tech. 1953.

12. Sundén, N. Svensk Kem. Tidsskr. 66 (1954) 20, 50, 173.

13. Sundén, N. Ibid. 66 (1954) 345.

14. Cozzi, D. and Vivarelli, S. Z. Elektrochem. 57 (1953) 408; 58 (1954) 907.

15. Carleson, B. G. F. and Irving, H. J. Chem. Soc. 19544390.

16. Irving, H. and Rosotti, F. J. C. Ibid. 1955 1927, 1938, 1946.

17. Burns, E. A. and Hume, D. N. J. Am. Chem. Soc. 79 (1957) 2704.

18. Kraus, K. A. and Nelson, F. A.S.T.M. Spec. Tech. Publ. 195 (1956).

19. Kraus, K. A. and Moore, G. E. J. Am. Chem. Soc. 75 (1953) 1457.

20. Johnson, J. S. and Kraus, K. A. Ibid. 79 (1957) 2034.

21. Robinson, R. A. and Stokes, R. H. Electrolyte Solutions, Butterworths, London 1955.

22. Woodward, L. A. and Bill, P. T. J. Chem. Soc. 19551699.

23. Sillén, L. G. Acta Chem. Scand. 10 (1956) 186.

24. Bjerrum, J., Schwarzenbach, G. and Sillen, L. G. Stability Constants of Metal-ion Complexes. Part II: Inorganic Ligands. Special publication No. 7 of the Chemical Society, London (1958).

Received October 27, 1961. 